\title{
A Study on Development of Dry Floor Heating System for Applying to Apartment Buildings of Korea
}

\author{
Yun-Chul Choi ${ }^{1}$ and Hung-Chan Jeon ${ }^{2 *}$ \\ ${ }^{1}$ Department of Building Equipment \& Fire Protection System, Chungwoon \\ University, Incheon, Korea \\ ${ }^{2}$ Department of Architectural Engineering, Suwon University, Hwaseong, Korea \\ ${ }^{1} 21 y c c h o i @$ chungwoon.ac.kr, ${ }^{2 *}$ chun4575@nate.com
}

\begin{abstract}
In this study, a kind of dry floor element (dry heat storage floor heating block) was developed for applying it to some kinds of residential buildings in Korea and the applicability of the element to some thermal environments and apartment buitaings was evaluated. In the aspect of thermal environments, the hed sinking and recuperation capacities of the existing wet floor system and the dry one for which a ary heat storage floor heating block is applied were compared. And the applicability of the block to apartment buildings was evaluated by analyzing the strength and the floor impact noise levels. As the results from a thermal environment analysis, it was analyzed that the heat sinking capacity of a dry floor structure which applies a dry heat storage floor heating block is inferior to a wet floor structure,by@ a litle, but the heat sinking capacity of a dry floor structure is higher than that of a wet one. In addition, since the average strain and the residual one were $0.21 \mathrm{~mm}$ and $013 \mathrm{~mm}$ respectively and the lightweight and heavyweight floor impact noise level, were $39 \mathrm{~dB}$ and $54 \mathrm{~dB}$ respectively as the results from a local compression test, it weds analyzed that the dry floor structure satisfies the Korean Industrial Standards (KS)
\end{abstract}

Keywords: Apartment Buildings, Dry Floor Heating System, thermal environment, Heat storage, Floor impact noise

\section{Introduction}

\subsection{Background and Purpose of Study}

Recently in Korea, dry construction methods are being proliferated for the reasons of shortening the construction period, securing economic feasibilities and good quality during the construction of a building and the easiness of maintenance thanks to a longer lifespan of a building[1]. And also, many kinds of construction methods for drying the apartment buildings that take most portion of the Korean residential buildings have been developed.

In Korea, the sedentary lifestyle has been generalized from the old days due to the country's unique radiant floor heating system for the traditional residential houses so called, "Ondol". And such heating system, "Ondol" is applied even in these days. However, the floor heating system which is currently applied has some critical defects since some cushioning materials (heat insulation materials) are installed over the slab layer first, some ALC (Autoclaved Lightweight Concrete) is cast over the cushioning materials, some heating pipes are installed and finally the floor is finished with mortar and the current system has a weakness since it is hard to secure a good quality.

Even though some kinds of dry construction methods have been developed in order to replace some heating pipes and mortar thermal insulating materials for solving such kinds 
of defects mentioned above, those methods also have some problems, such as, a lower strength compared to the existing floor system, noise between floors and a phenomenon which a heat storage capacity which is needed for a residential house is extremely lowered, etc.

Accordingly, in this study, it is intended to develop a dry floor element while taking into consideration of the heat storage capacity and to evaluate the applicability of the element to an apartment building as a type of residential building which takes most portion of Korean residential buildings after analyzing the thermal environments, strengths and floor impact noise levels.

\subsection{Scope and Method of Study}

In this study, a dry heat storage floor heating block which can be applied to some kinds of residential buildings, especially, to an apartment building was developed while taking, consideration of the variability, remodeling and recycling of the indoor spaces And the applicability of the heating block to an apartment building was evaluated by conmaring the thermal environments, strengths and floor impact noise levels of the dry floor heating block with those of the existing wet one.

The study procedure is as follows.

First, a dry heat storage floor heating block is develobed by researching the application status of such a floor heating structure and the relevant studies by conducting some theoretical examinations.

Second, a specimen for which the existing wet construction method and a dry one are applied is made in order to evaluate the thermal environment of a dry heat storage floor heating block and those thermal environments (floon surface temperatures and heat dissipation characteristics) of two kind Cor blocks are compared and evaluated.

Third, the appropriateness of the floor element is evaluated by measuring the strain of a dry heat storage floor heating block after applying some local load and impact load onto it.

Fourth, the impact noise insulation performances of the lightweight and heavyweight floors of some apartment buldings whose floors are made of some dry heat storage floor heating blocks werê evaluated.

\section{Theoretical Reviews}

\subsection{Wet Floor Structure (Standard Floor Structure)}

A kind of floorheating structure which is mainly used in Korea is composed of slab as the lowest layer bearing some load, some insulation materials for preventing some thermal loss over the slab, some heat storage materials which store and radiate some heat and some finishing materials on the top as can be seen in the following Figure 1[2]. Moreover, laking into consideration of the 'Notification No. 2013-33 of the Ministry of Land Infrastructure and Transport, [Floor impact sound insulation structure approval and management standards for apartment buildings.]' that was announced in 2013, 5 kinds of standard floor structures are defined and suggested as can be seen in Figure 2[3]. Among such 5 kinds, the Standard Structure No. 2 is used the most for apartment buildings in these days in Korea. 


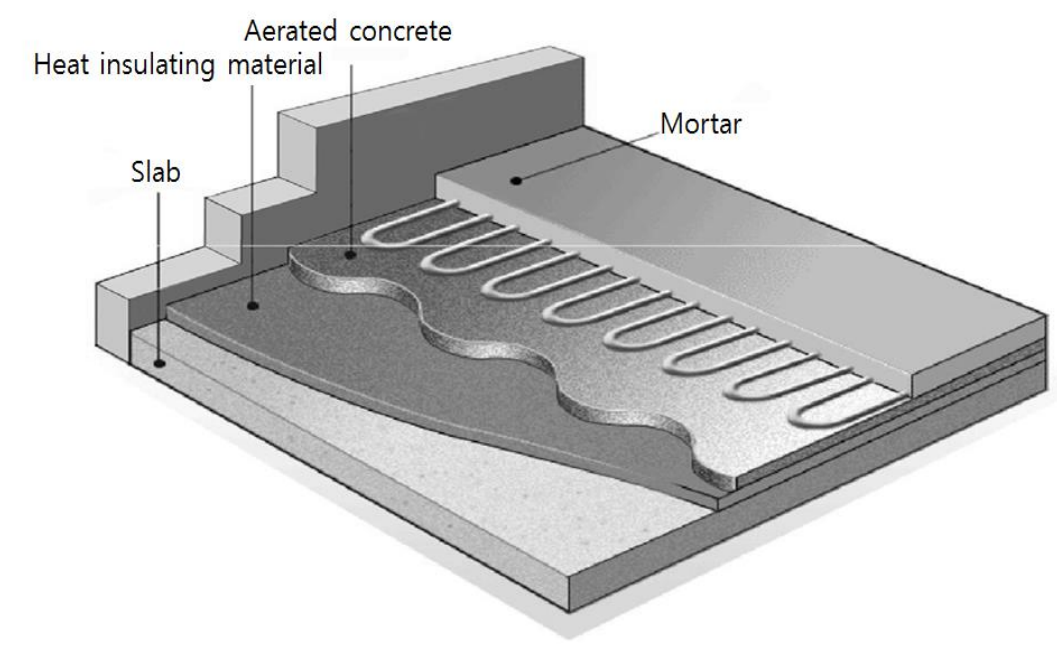

Figure 1. Structure of a Wet Floor Heating System

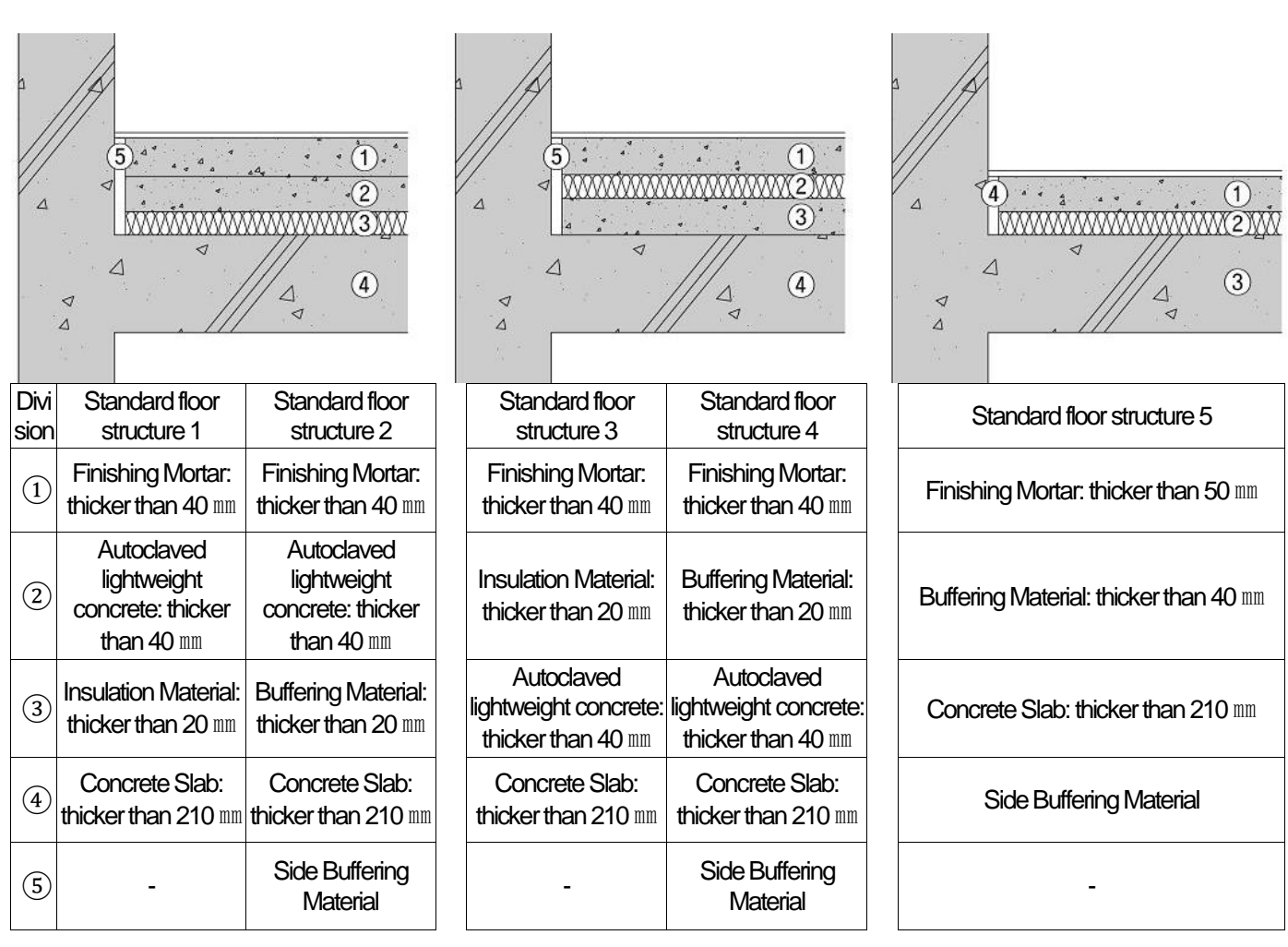

\section{Figure 2. Standard Floor Structure for Apartment Buildings}

While double insulation materials or sound absorbing materials can be used for a dry floor system, a wet construction method is applied to the parts where floor pipes are installed for the full scale of floor heating function and the finishing mortar is cast since such parts are not dried. However, since it takes much time to cure mortar used for a wet floor structure, it has a big effect on the total construction period and it is hard to maintain since the whole floor area must be reconstructed when a problem occurs.

\subsection{Dry Floor Heating System}

As dry floor structures for floor heating systems which have been developed until now, there are two kinds of structures, that is, a double floor structure for which a floor plate, insulation material, heating piping and thermal radiation board are modularized and an 
EPS panel method which some heating panels are combined with some thermal radiation boards into which some heating pipes can be inserted[4]. (Figure 3)

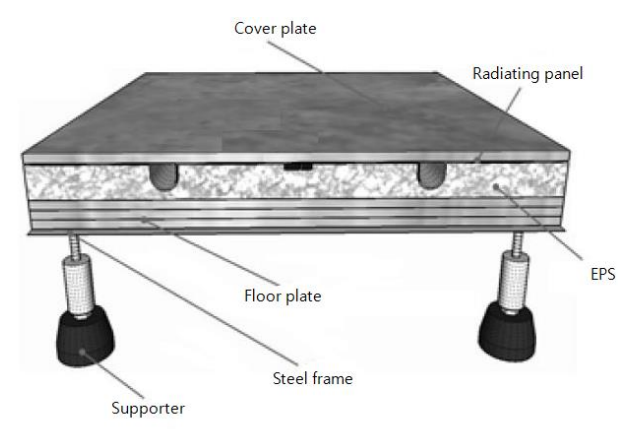

Double Floor Method

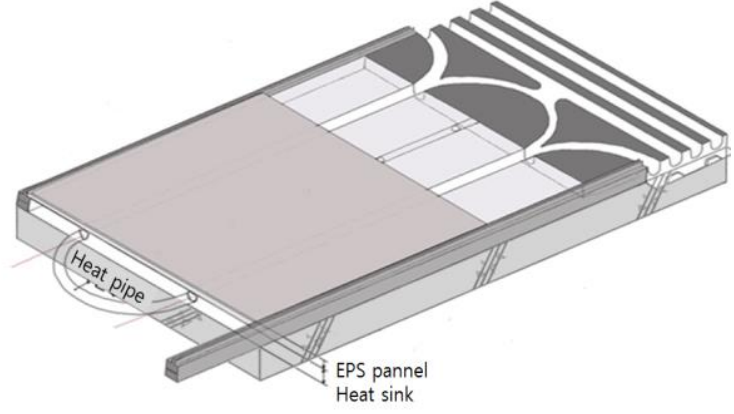

EPS Panel Method

Figure 3. Structure of Dry Floor Heating System

However, regarding to the dry floor structures that have been developed until how have some problems, it is hard to expect a good heat storage pefformance with those dry floor structures since there are no appropriate heat storage materials even though the workability is excellent and the economic feasibilities and strengths of such dry floor structures are inferior to a wet floor structure[5][6] 7]. Moreoven it is in the condition that it is hard to use such a dry floor structure for an apartment building since the floor structure of an apartment building must have the same structure as the standard floor structure or must be accredited in accordance with the accreditation standards and procedure of the floor structure impactnoise insulation performance that is specified in the Apartment Building Floor Impact Noise Insulation Structure Accreditation \& Management Standards[8], but such a floor structure does not satisfy such conditions.

\section{Development of Dry Heat Storage Floor Element}

\subsection{Overview of Floor Heating Blocks}

As mentioned earlier, in order to apply a dry floor structure to a Korean apartment building, the froor structure must be the same as the standard floor structure. Since the parts where some insulation material (or buffering one) and autoclaved lightweight concrete can be applied among the standard floor structure can be made or constructed in a dry method, in this study, a floor heating block which dries the mortar part of the existing wet floor structure is developed[9].

To make a floor heating block, the heat storage and radiation performances must be considered, first. And next, since the workability and economic feasibility must be conside ed together, the floor heating block was made by using the same cement mortar as that for the existing wet floor structure. However, since the construction part of a wet floor system is structured as one plate type, it is easy to satisfy the strength required for a floor structure, but since this floor heating block is installed by fixing many pieces for arrangement, some VAE resin, etc., is applied in order to enhance the strength of the block itself.

The blending ratio of the materials for the dry floor hating block is suggested in the following Table 1.

Table 1. Mixing Ratio of Materials for Dry Floor Heating Block 


\begin{tabular}{|c|c|c|}
\hline Category & Mixing ratio(\%) & Material \\
\hline Binder & 45 & Portland cement, Alumina cement, Anhydridgips \\
\hline Aggregate & 50 & Sand \\
\hline Chemical & 5 & $\begin{array}{c}\text { HPMC, VAE polymer, Starch, Antifoaming agent, } \\
\text { Dispersing agent }\end{array}$ \\
\hline
\end{tabular}

\subsection{Shape and Composition of Floor Heating Block}

Considered the shape of the floor heating block, $200 \mathrm{~mm}$ of basic interval between floor heating pipes are applied since the existing heating piping must be applied and the block is made having the straight and curved lines in the shapes shown in the Figure 4 taking into consideration of the installation of the heating pipes.
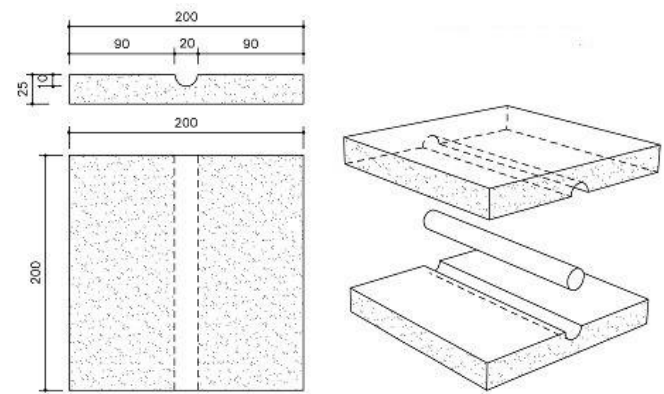

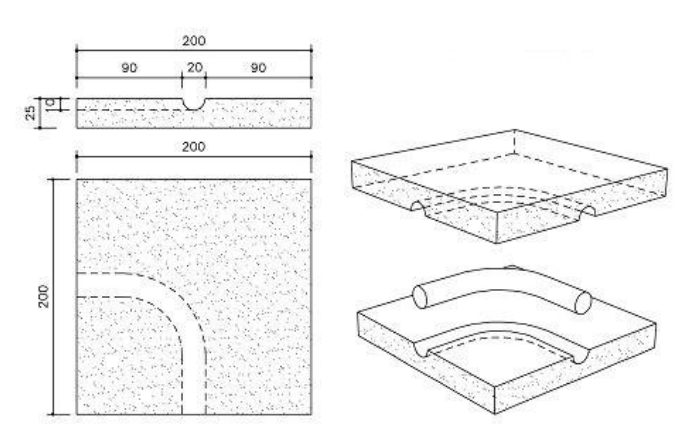

Figure 4. Shape of Floor Heating Block

The floor structure using the floor heating block is shown in the following Table 2.

Table 2. Floor Structure using the Floor Heating Block

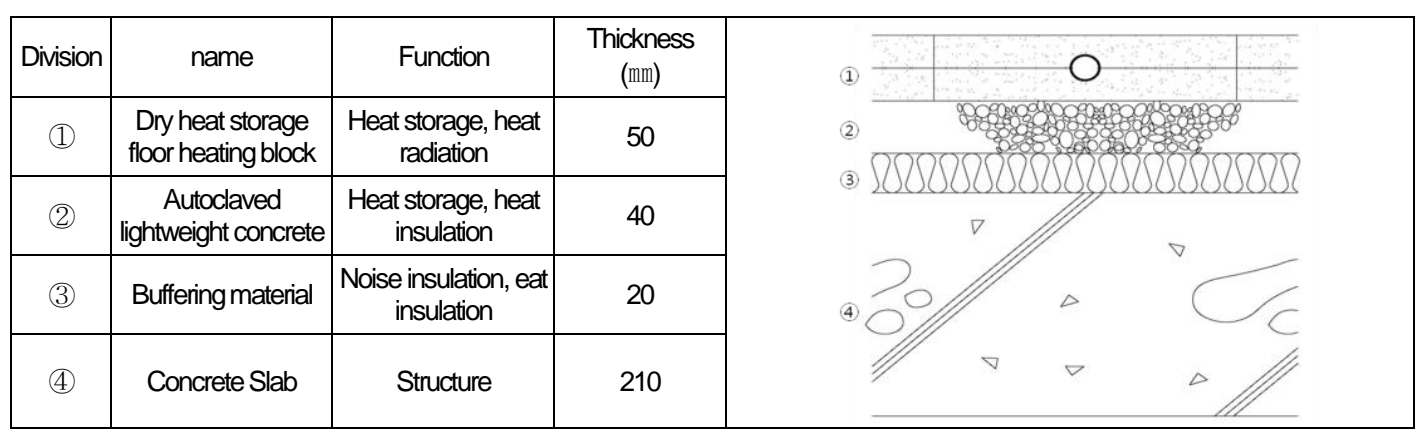

\section{Thermal Environment Evaluation}

\section{Composition of Specimen}

A specimen was made for comparing the thermal environments of the existing wet construction method and a dry heat storage construction method using a dry heat storage floor heating block. For the specimen, two $1,200 \mathrm{~mm} \times 1,200 \mathrm{~mm}$ of rooms were created inside $3,000 \mathrm{~mm} \times 6,000 \mathrm{~mm}$ of space were created and the existing wet floor structure and the dry heat storage floor structure shown in Table 2 were applied.

A boiler which can supply some hot water at a certain level of temperature was installed to the heating piping for an experiment. The temperature of hot water is adjusted by the TCU (Temperature Control Unit) that is attached to the boiler and such hot water is supplied by using the circulation pump inside the boiler. For the experiment, the temperature of the supplied hot water was set at $50^{\circ} \mathrm{C}$ or $60^{\circ} \mathrm{C}$ and the hot water supply 
time was set to be supplied for more than 24 hours and then to be stopped. A T-type thermocouple wire was installed on the floor surface and inside, heating piping and indoor center for measuring temperature and was attached by covering it with some Aluminum foil tape. And the measured temperature data was collected every minute by using a data logger. The temperature measuring points are suggested in the following Table 3.

Table 3. Temperature Measuring Points

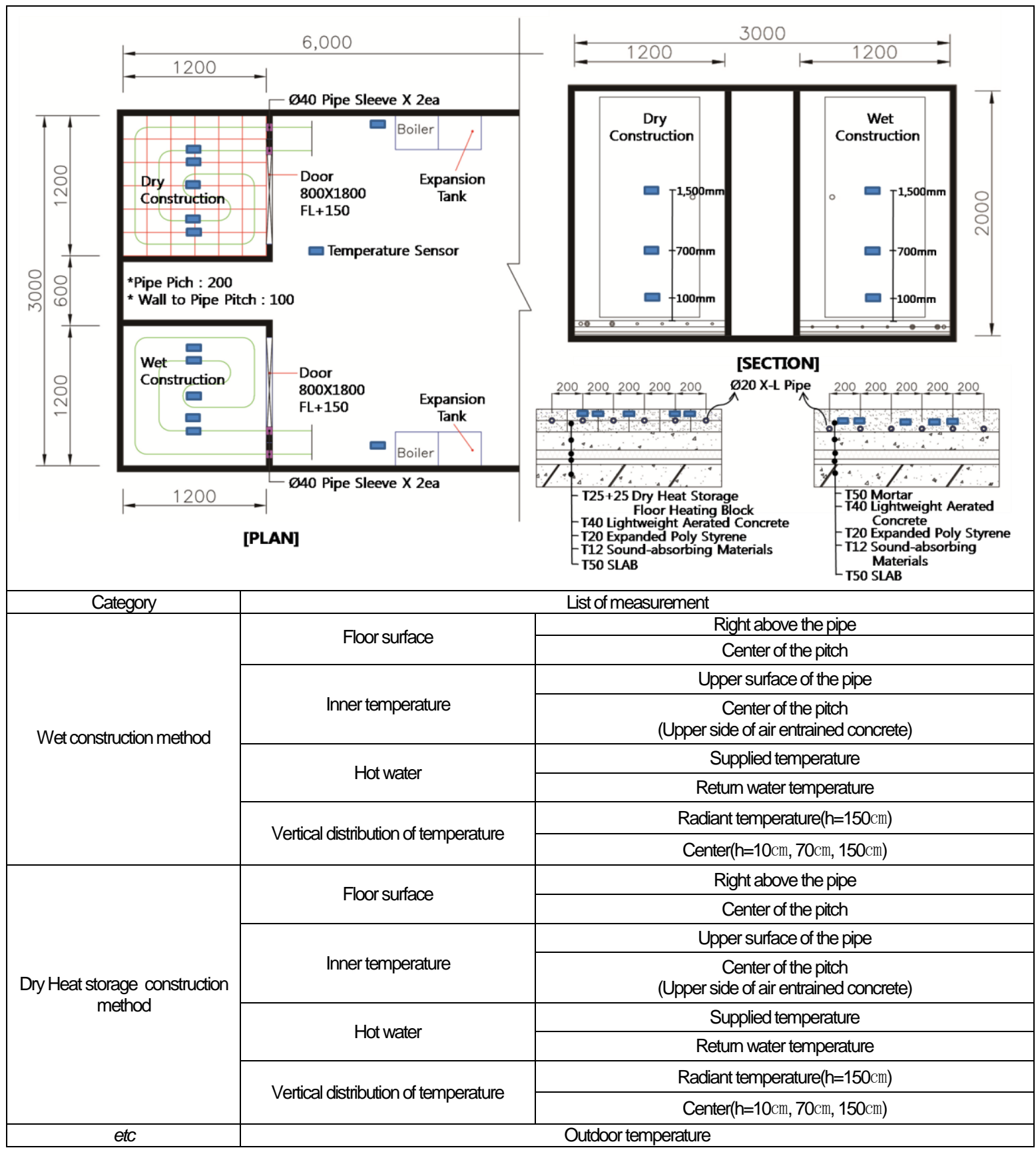

\subsection{Analysis Results of Floor Surface Temperature}


The following Figure 5 shows the floor surface temperatures of a wet floor structure and a dry one.
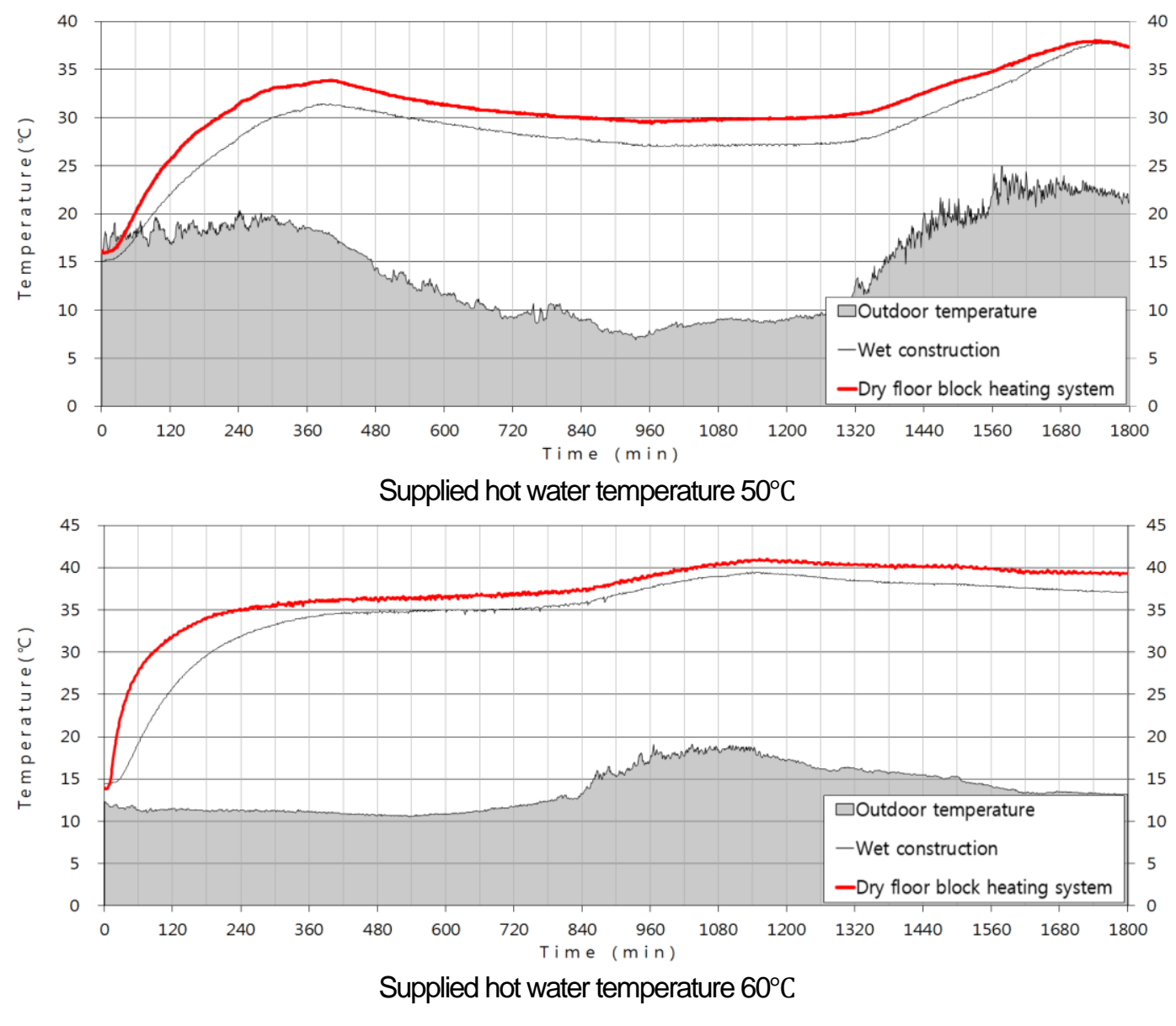

Figure 5. Distribution of Average Floor Surface Temperatures (Supplied Hot Water)

Figure 5 shows the average temperature of every each floor surface and outdoor air temperature changing as time passes away when each of $50^{\circ} \mathrm{C}$ and $60^{\circ} \mathrm{C}$ hot water is supplied under the condition that each floor surface is cooled enough. The initial floor surface temperature before conducting the experiment was at $15^{\circ} \mathrm{C} \pm 0.7^{\circ} \mathrm{C}$ when the supplied hot water temperature was $50^{\circ} \mathrm{C}$ and was at $14^{\circ} \mathrm{C} \pm 0.5^{\circ} \mathrm{C}$ when that was $60^{\circ} \mathrm{C}$. Thus, it was found that the initial condition before each experiment was the same.

The average temperature of floor surface was affected by a little by the hot water temperature and the outdoor air temperature. However, in case of a wet floor structure, the temperature was stabilized in around 240minutes generally and in case of a dry heat storage one, it was stabilized in around 320 minutes. It was analyzed that the temperature of a wet floor structure was higher by $3.3^{\circ} \mathrm{C} \& 3.0^{\circ} \mathrm{C}$ at maximum when the supplied water temperature was $50^{\circ} \mathrm{C}$ and $60^{\circ} \mathrm{C}$ respectively considered the temperature difference between the wet floor structure and the dry one after the floor surface temperature is stabilized.

As the results from researching on the difference between the surface temperature of the straight upper part of the piping and the surface temperature between pipes in order to judge the distribution of the floor surface temperatures, it was found that the average temperature of a wet floor structure was $3.1^{\circ} \mathrm{C}$ and that of a dry one was $3.3^{\circ} \mathrm{C}$ when the supplied hot water temperature was $50^{\circ} \mathrm{C}$, but when the supplied hot water temperature 
was $60^{\circ} \mathrm{C}$, the average temperatures of both systems were $4.6^{\circ} \mathrm{C}$ and $4.3^{\circ} \mathrm{C}$ respectively. Thus, it was analyzed that both average temperature are lower than $5^{\circ} \mathrm{C}$ and conform to the KS(Korean Industrial Standards) Specifications[10].

The following Figure 6 shows the changes in the surface temperatures due to the discontinuation of hot water supply.
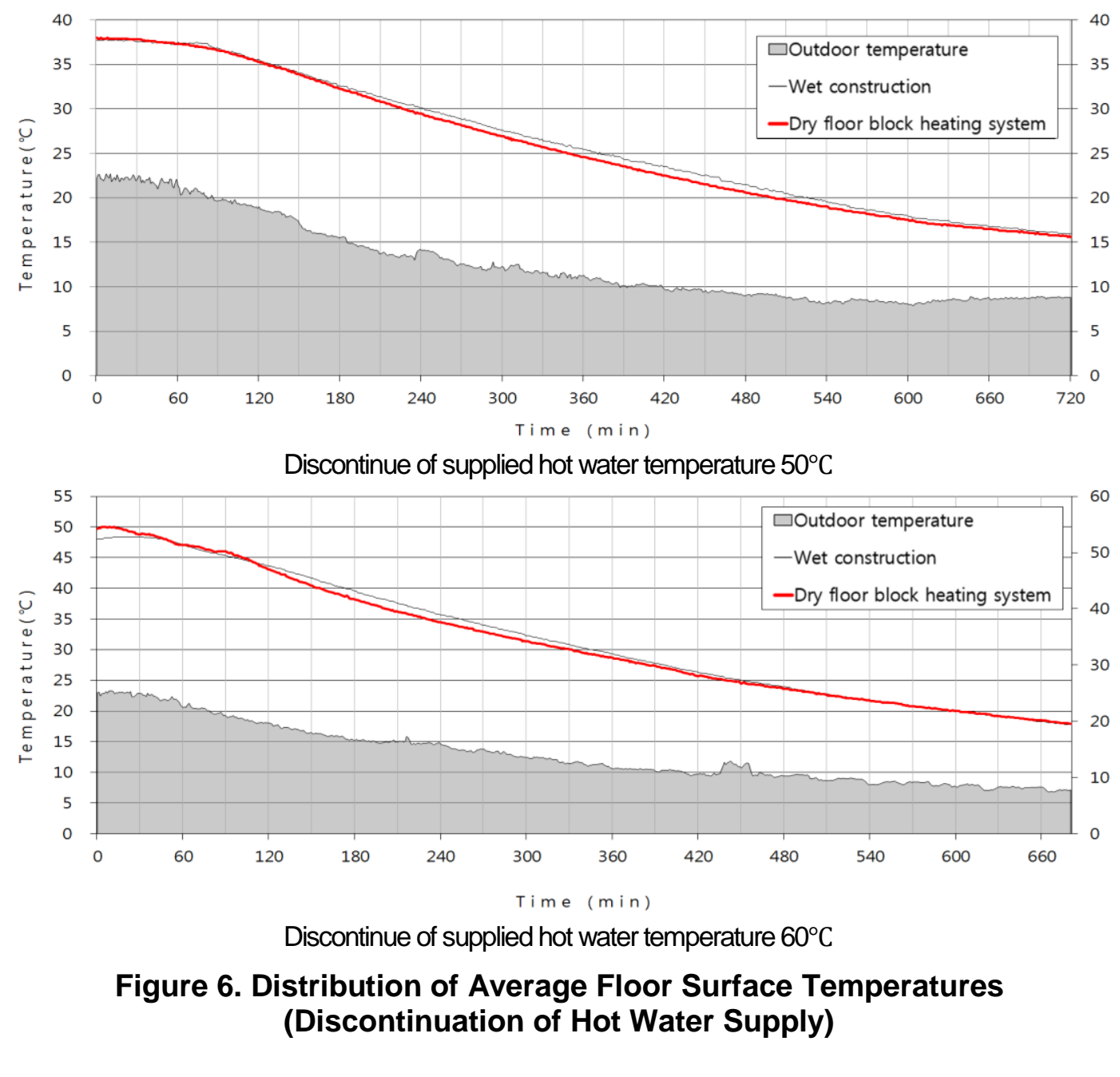

For checking the heat storage performance, the time spent until the floor surface temperature has a difference by $\Delta 20^{\circ} \mathrm{C}$ was analyzed by measuring the changes in the average floor surface temperature depending on the discontinuation of hot water supply.

As the analysis results, it was found that around 577minutes and 328minutes were taken when the supplied hot water temperature was at $50^{\circ} \mathrm{C}$ and $60^{\circ} \mathrm{C}$ respectively in case of a wet floor system and 610 minutes and 384 minutes were taken when that was at $50^{\circ} \mathrm{C}$ and $60^{\circ} \mathrm{C}$ respectively in case of a dry floor structure. Thus, it was analyzed that a dry heat storage floor structure is better than a wet one in the aspect of the maintenance of floor surface temperature thanks to the heat storage effect of the specimen after some hot water supply was discontinued. 


\section{Evaluation of Strengths and Floor Impact Noise Levels}

\subsection{Local Compression Test Results}

A local compression test was conducted to measure the strength of a block. The test was conducted by measuring the strain and the residual strain under the designated load of each part while maintaining $980 \mathrm{~N}$ of load onto one (1) compression bar whose diameter is $25 \mathrm{~mm}$ and whose ends are curved for one minute at the position shown in the following Figure 7 in accordance with the KS B 8025[10].
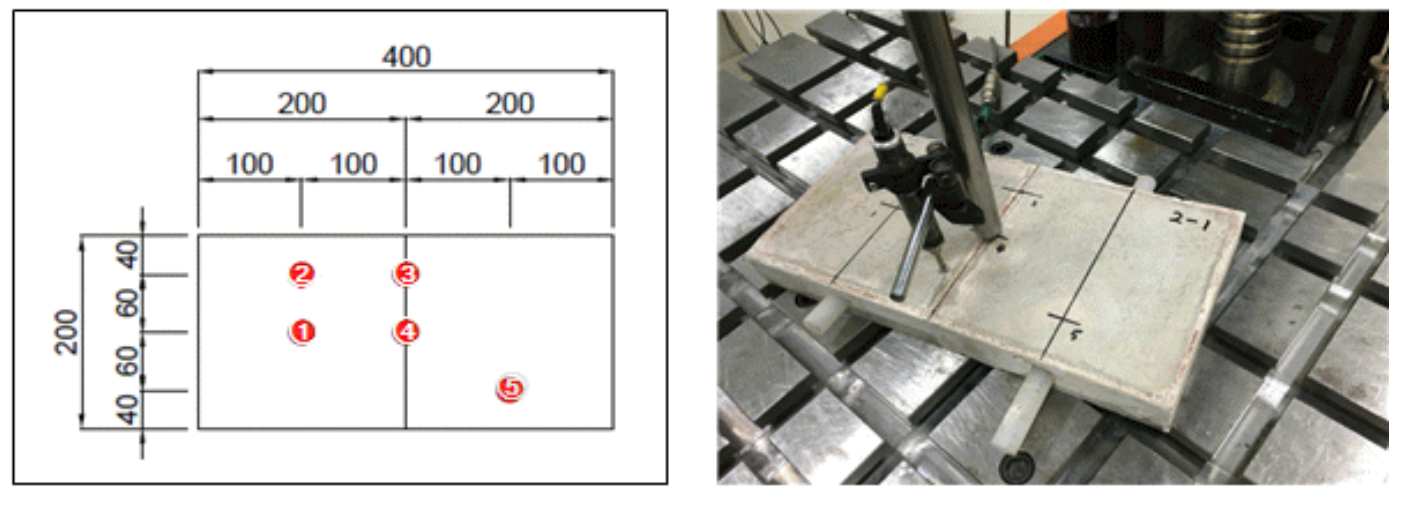

Figure 7. Measuring Positionand Test-related Photos (Measured Parts)

3 same specimens were made and the strain of each one was measured. And the measurement results are shown in the following Table 4.

Table 4. Strain caused by Local Compression Test

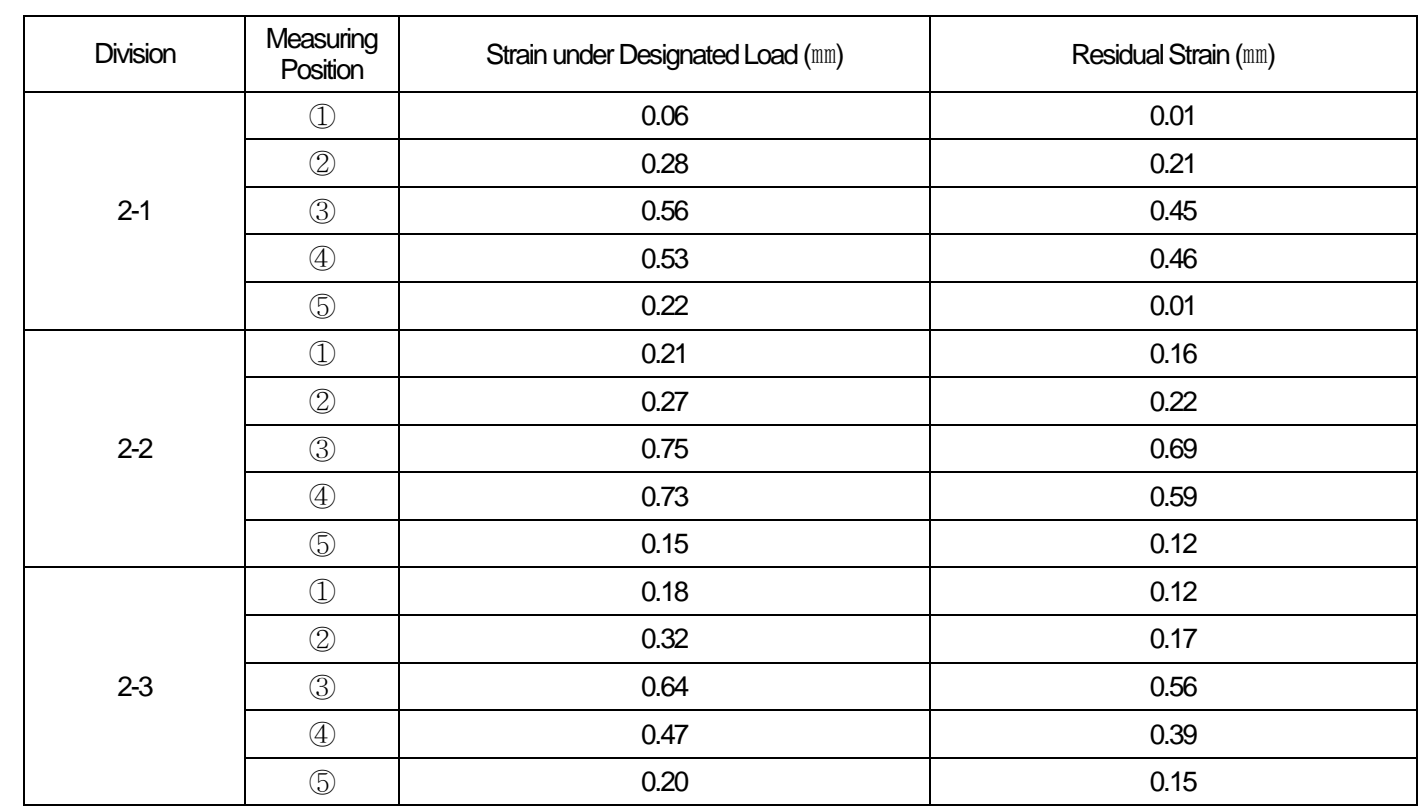

It was found that the strain of the adhered part of the block (3) was $0.75 \mathrm{~mm}$ and the residual strain of that was $0.59 \mathrm{~mm}$ under the designated load as the highest ones while a level of load is applied. And it was analyzed that the average strain of the adhered parts (3) \& (4) was $0.61 \mathrm{~mm}$ and the residual strain of that was $0.52 \mathrm{~mm}$ under a designated load. In addition, since the average strain of the rest parts, (1), (2) \& (5) excluding the adhered 
parts was $0.21 \mathrm{~mm}$ and the residual strain of that was $0.13 \mathrm{~mm}$ under a designated load, the strengths of the adhered parts and blocks satisfy the KS specifications at $5 \mathrm{~mm}$ of average strain and $2 \mathrm{~mm}$ of residual one.

\subsection{Floor Impact Noise Test Results}

Floor Impact Noises are measured in accordance with the test method specified in KS F 2810[11][12] and the values were calculated by the Inverse A-weighted Value specified in KS F 2863[13][14]. The test procedure in accordance with KS F 2810 is as follows. Some impact noises are generated onto the test target floors by using a tapping machine and a bang machine. At this time, 5 impacted positions in total were decided including one central point within the floor surface that is $0.5 \mathrm{~m}$ far from the surrounding wall of the relevant room. In order to measure the average sound pressure level of each floor impact noise, $\mathrm{dB}$ was measured by installing a microphone above 4 positions of the height while putting it $0.7 \mathrm{~m}$ away from the test target ceiling.

The measurement equipment, the cross-section of the test room and the calculation results of floor impact noise levels are shown in the following Tables $5 \& 6$.

\section{Table 5. Floor Impact Noise Measurement Equipment and} Cross-Section of Test Foom
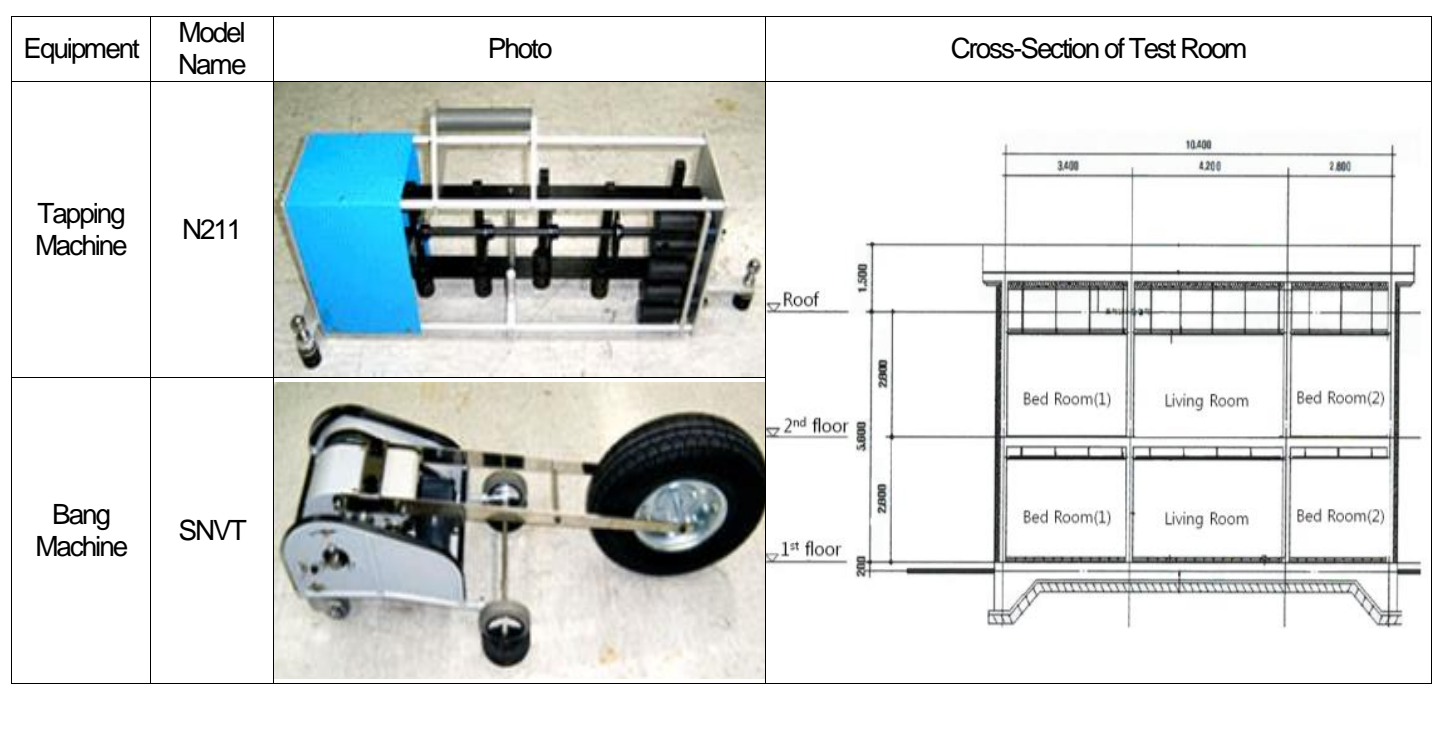

Table 6. Calculation Results of Floor Impact Noise Levels

\begin{tabular}{|c|c|c|c|}
\hline Divis & Center Frequency $(\mathrm{Hz})$ & $\begin{array}{c}\text { Normalized Floor Impact Noise } \\
\text { Level (dB) }\end{array}$ & $\begin{array}{l}\text { Inverse A Weighted Nomalized } \\
\text { Floor Impact Noise Level (dB) }\end{array}$ \\
\hline & 125 & 60.6 & \multirow{5}{*}{39} \\
\hline & 250 & 41.1 & \\
\hline Machine & 500 & 38.8 & \\
\hline & 1,000 & 33.2 & \\
\hline & 2,000 & 34.6 & \\
\hline \multirow{4}{*}{ Bang Machine } & 63 & 81.7 & \multirow{4}{*}{54} \\
\hline & 125 & 70.2 & \\
\hline & 250 & 47.7 & \\
\hline & 500 & 39.6 & \\
\hline
\end{tabular}

As the results from an analysis of floor impact noise levels, it was found that the lightweight impact noise level was the first grade (less than $43 \mathrm{~dB}$ ) as the highest grade 
that is suggested by the Ministry of Land, Infrastructure and Transport and the heavyweight impact noise level was the fourth grade $(47 \sim 54 \mathrm{~dB})$

\section{Conclusion}

In this study, the thermal environment, strength and floor impact noise performance of the heat storage floor heating block that was developed for drying a floor heating system which is applicable to an apartment building were evaluated and the following research results were drawn.

(1) A dry heat storage floor heating block which can be applied to an apartment building was developed through an analysis of the existing wet floor structure and a dry one which was recently developed. In order to evaluate the applicability of those floor structures to an apartment building, the thermal environments, strengths and floor impact noise levels of both floor structures were analyzed.

(2) In case of the thermal environments, the thermal radiation and storage performances depending on the supply of hot water were compared and evaluated by establishing a specimen for the existing wet floor structure and the dry one to which a dry heat storage floor heating block is applied. The experiment was condueted while measuring the average surface temperatures as time passes aw ay when $50^{\circ}$ and $60^{\circ} \mathrm{C}$ of hot water are supplied and hot water supply is discontinued after each floor surface was cooled enough. The average floor surface temperature of both kinds of floor structures were compared to find out the thermal radiation performances of both kinds of floor structures. As the analysis results, it was found that the floor surface temperature of a wet floor structure rises more quickly than that of a dry one. It was analyzed that the temperature difference of a wet floor strueture after the floor surface temperature is stabilized is lower by around $3^{\circ} \mathrm{C}$ than hat of a dry one. To check the heat storage performance, the average floor temperature after discontinuing the hot water supply was measured. As the analysis results, it was analyzed that a dry floor structure is better than a wet one in the aspect of maintaining the loo surface temperature thanks to the heat storage effect of the structure after discontinting the hot water.

(3) For checking the strengths, a local compression test was conducted for the floor heating block. Accordingly, the strains were measured and evaluated. It was found that the average straipand the residual one of the adhered parts of the block were $0.61 \mathrm{~mm}$ and $0.52 \mathrm{~mm}$ respectively. And it was analyzed that the average strain and the residual one of the rest areas excluding the adhered parts were $0.21 \mathrm{~mm}$ and $0.13 \mathrm{~mm}$ respectively. Thus, those floor heating blocks conform to the KS Specifications.

(4) For checking the floor impact noise levels, the lightweight noise and heavyweight one were measured and evaluated by using a tapping machine and a bang one. As the analysis results of floor impact noise levels, it was found that the lightweight impact noise level (43aB/ was the first grade as the highest one that is suggested by the Ministry of Land, Infrastucture and Transport and the heavyweight impact noise level(47 54dB) was the fourth grade.

As the results drawn from above, it was found that a dry heat storage floor heating block has the same thermal environment performance as that of the existing wet-type block, but has better heat storage performance than the wet-type one and satisfies all of the performances required for a floor surface of a Korean apartment building. In addition, a dry floor structure has better workability than a wet one, so it is effective to shorten the construction period and the economic feasibility can be secured when mass production is progressed. And it is considered that a dry-type block has a high possibility to be applied to an apartment building since it is eco-friendly because it can be recycled as well as it can be easily maintained. 


\section{Acknowledgments}

This work was supported by Business for cooperative R\&D between industry, Academy, and Research institute funded Korea Small and Medium Business Administration (Grants No.C0352298)

\section{References}

[1] N.H. Kim, "Evaluating the Environmental Performance of Ondol and Developing a Dry Double-Floor Hydronic Ondol System”, Master's thesis, Hanyang University (2006)

[2] S.K. Pang, D.W. Lee and O.J. Shim, "The Estimate of Thermal Capacity about Artificial Light-weight Gravel Ondol made from Fly-ash”, Proceeding of The Architectural Institute of Korea, Seoul, Korea, Vol.12. No.1, (1992) April, pp.183-186.

[3] Ministry of Land, Infrastructure and Transport, "MOLIT notification no.2013-33: Floor impact sound insulation structure approval and management standards for apartment buildings", (2013).

[4] J.H. Su and Y.H. Jung, "Analysis on Heat Retrieving Characteristics of the Pre-fabricated OndoI System and Existing Ondol System, "Journal of The Construction and Environmental Research Institute, Vol.5, No.1, (2010), pp.1-9.

[5] B.W. Ahn and Y.T. Shin, "The Establishment of the Optimum Operating Conditions in Ondol", Journal of The Architectural Institute of Korea, Vol.12, No.4, (1996), pp.129-140.

[6] B.W. Ahn and J.Y. Sohn, "The Composition of Effective Floor Structure in Ondo/ Heating System", Journal The Korea Society of Living Environmental System, Vol.4, No.4, (1997), pp. 717.

[7] G.D. Lee, J.H. Kim, C.H, Jeong, D.W. Kim and O. Keiichiro, "A Study on the Development of Rolled Dry Floor Heating System for Improving Workability,", Journal of The Korea Institute of Building Construction, Vol.12. No.2, (2012), pp.177-180.

[8] Ministry of Land, Infrastructure and Transport, "MOLIT notification no.2015-1108: Energy saving designing standard of buildings.", (2015).

[9] Y.C. Choi, H.C. Jeon, H.D. Kim, M.E. Lee and I.H. Cho, "A Study on the Development of Dry Floor Heating System Member with Thermal Storage, Proceedings of 10th International Workshop on Mechanical Engineering 2016, Architecture and Ciyil Engmeering 2016, Jeju, Korea, Vol.2 (2016) August 16-19, pp.55-59.

[10] Ministry of Trade, Industry and Energy "Korean Industrial Standard no.KS B 8025:2010 Floor panels

[11] Ministry of Trade, Industry and Energy, "Korean Industrial Standard no.KS F 2810-1:2001 Field measurements of impact sound insulation of floors - Part 1: Method using standard light impact source", (2015).

[12] Ministry of Trade, Andustry and Enêrgy, "Korean Industrial Standard no.KS F 2810-2:2001 Field measurements of floor impact sound insulation of buildings - Part 2: Method using standard heavy impact sources", (2015).

[13] Ministry of Trade, Industry and Energy, “Korean Industrial Standard no.KS F 2863-1:2002 Rating of floor impact sound insulation for impact source in buildings and building elements - Part 1 : Floor impact sound insulation against standard light impact source", (2012).

[14] Ministry of Trade, Industry and Energy, "Korean Industrial Standard no.KS F 2863-2:2007 Rating of floor impact sound (nstation for impact source in buildings and building elements - Part 2 : Floor impact sound insulation against standard heavy impact source", (2012).

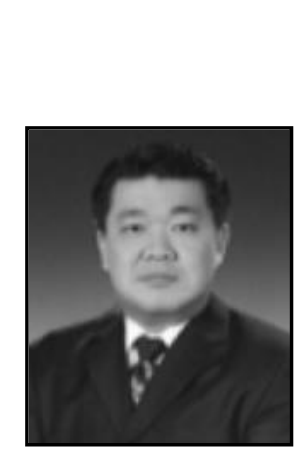

\section{Authors}

Prof. Yun-Chul Choi at present has been working as a professor in Dept. of Building Equipment \& Fire Protection System, Chungwoon University, Incheon, Korea. He was awarded Ph.D. by Hanyang University in 2008 in Building construction.

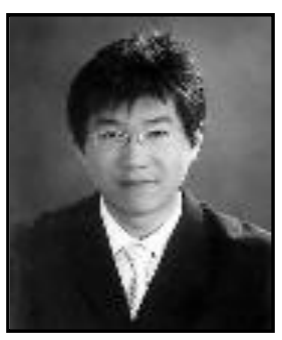

Hung-Chan Jeon at present has been working as a senior researcher in Architectural environmental laboratory, Suwon University, Hwaseong, Korea. He was awarded Ph.D. by Suwon 
University in 2016 in architectural environment \& Equipment engineering.

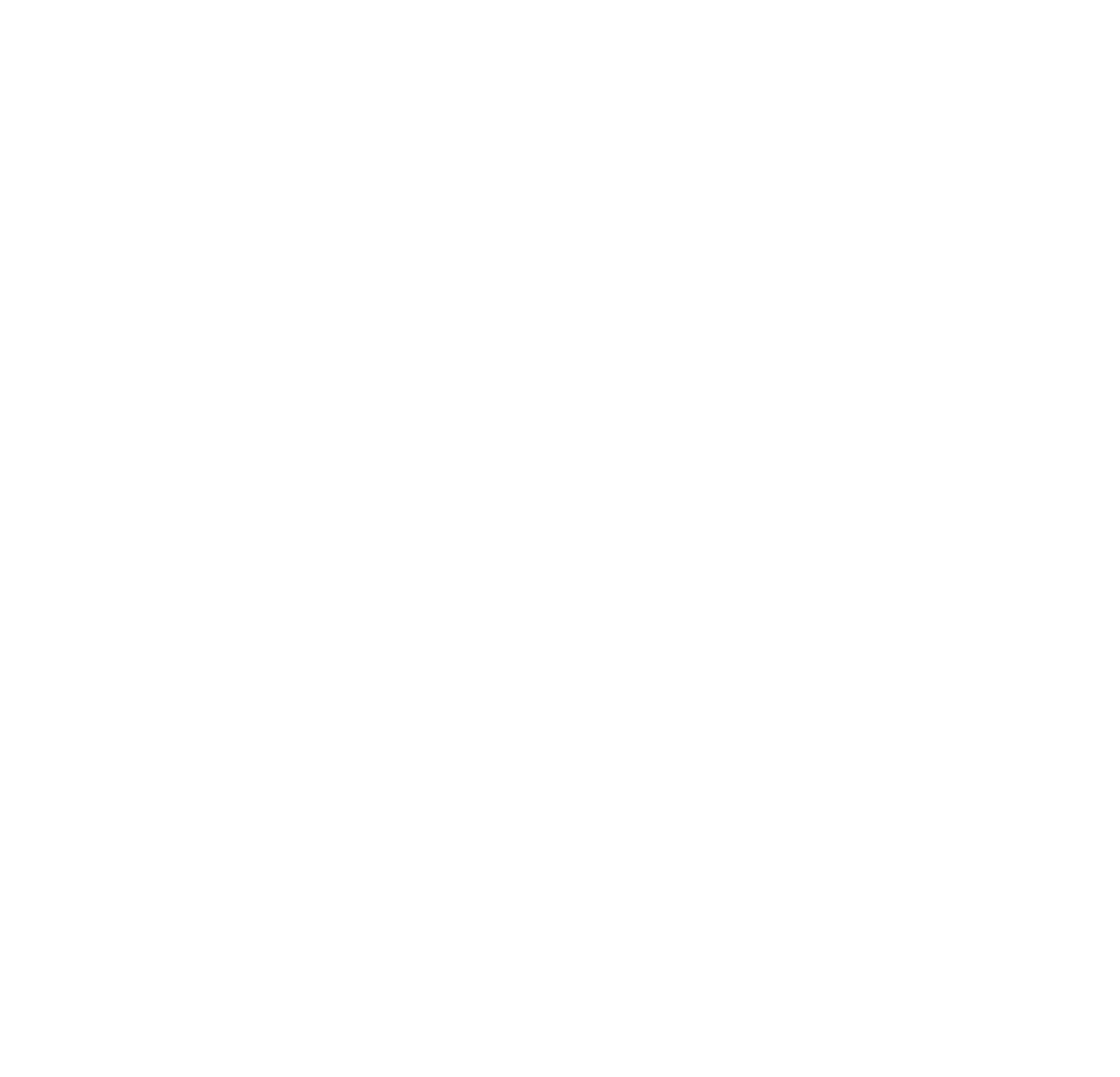


International Journal of Smart Home

Vol.10, No.10 (2016)

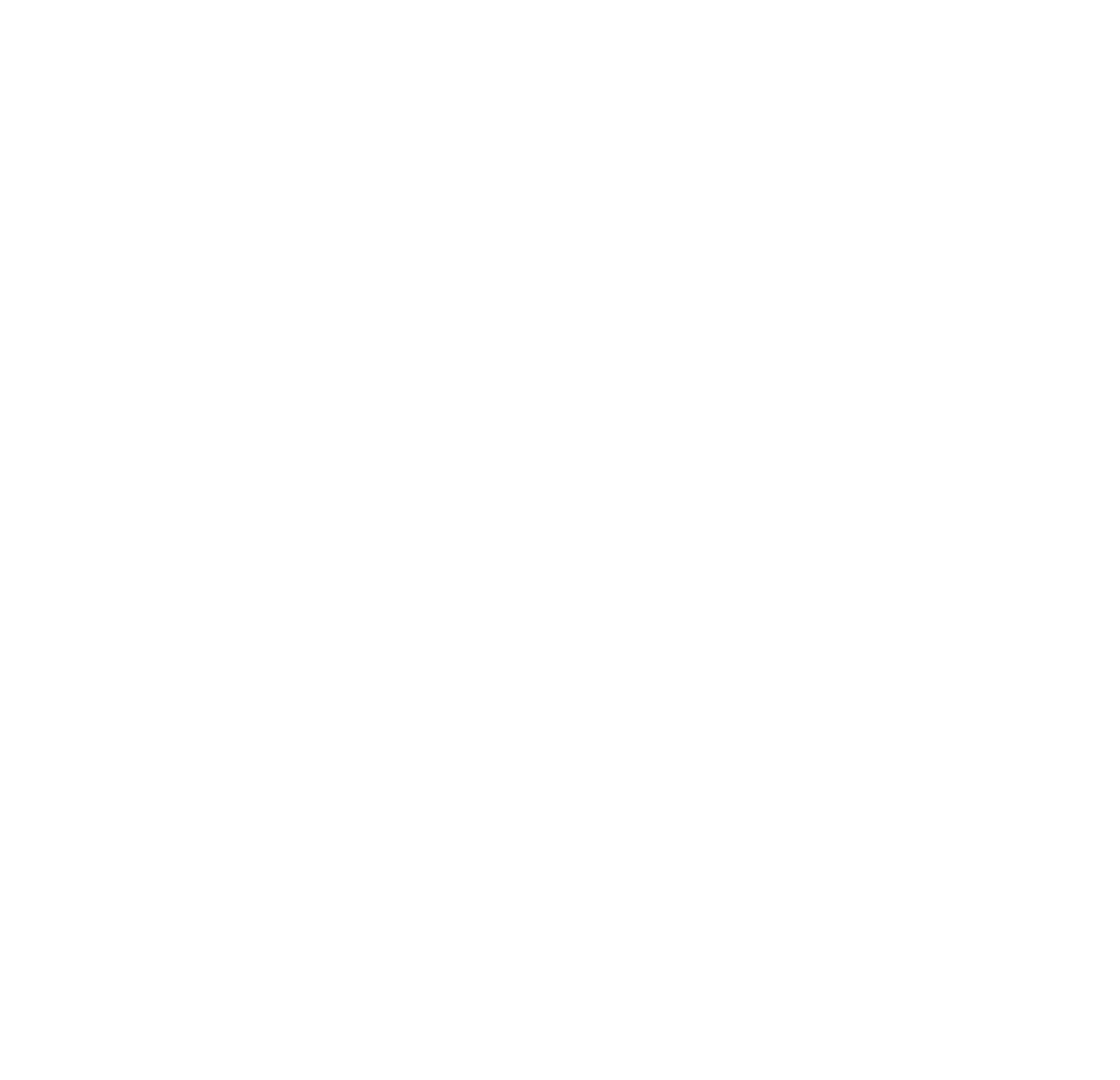

